\title{
Optical Imaging of Long-Term Depression in the Mouse Cerebellar Cortex In Vivo
}

\author{
Wangcai Gao, ${ }^{1}$ Robert L. Dunbar, ${ }^{1}$ Gang Chen, ${ }^{1}$ Kenneth C. Reinert, ${ }^{1}$ John Oberdick, ${ }^{2}$ and Timothy J. Ebner ${ }^{1}$ \\ ${ }^{1}$ Department of Neuroscience, University of Minnesota, Minneapolis, Minnesota 55455, and ${ }^{2}$ Department of Neuroscience and the Neurobiotechnology \\ Center, The Ohio State University College of Medicine, Columbus, Ohio 43210
}

Conjunctive stimulation of climbing fiber and parallel fiber inputs results in long-term depression (LTD) at parallel fiber-Purkinje cell synapses. Although hypothesized to play a major role in cerebellar motor learning, there has been no characterization of the cellular and molecular mechanisms of LTD in the whole animal, let alone its spatial properties, both of which are critical to understanding the role of LTD in cerebellar function. Neutral red optical imaging of the cerebellar cortex in the anesthetized mouse was used to visualize the spatial patterns of activation. Stimulation of the parallel fibers evoked a transverse beam of optical activity, and stimulation of the contralateral inferior olive evoked parasagittal bands. Conjunctive stimulation of parallel fibers and climbing fibers induced a long-term decrease (at least $1 \mathrm{hr}$ ) in the optical response to subsequent parallel fiber activation confined to the region of interaction between these two inputs. Activation of climbing fibers alone failed to induce the long-term decrease. Field potential recordings confirmed that the depression is postsynaptic and restricted to the interaction site. The long-term depression in the beam was prevented by a group 1 metabotropic glutamate receptor $\left(\mathrm{mGluR}_{1}\right)$ antagonist and was absent in transgenic mice selectively expressing an inhibitor of protein kinase $\mathrm{C}(\mathrm{PKC})$ in Purkinje cells. Conversely, the long-term depression occurred in the $\mathrm{mGluR}_{4}$ knock-out mouse, consistent with its postsynaptic origin. In addition to providing the first visualization of parallel fiber-Purkinje cell LTD in the cerebellar cortex, this study demonstrates the spatial specificity of LTD and its dependence on $\mathrm{mGluR}_{1}$ and $\mathrm{PKC}$ in vivo.

Key words: long-term depression; optical imaging; neutral red; cerebellum; mGluR; protein kinase C; parallel fiber; Purkinje cell

\section{Introduction}

Conjunctive stimulation of climbing fiber and parallel fiber inputs onto cerebellar Purkinje cells results in long-term depression (LTD) at parallel fiber-Purkinje cell synapses (Ito et al., 1982). Hypothesized to play a major role in cerebellar motor learning (Eccles, 1977; Mauk et al., 1998), parallel fiber-Purkinje cell LTD has been studied primarily in vitro using culture and slice preparations (Sakurai, 1987; Crepel and Krupa, 1988; Linden et al., 1991; Hartell, 1994; Lev-Ram et al., 1997) and also has been shown to exist in decerebrate animals (Ito and Kano, 1982; Ito et al., 1982; Ekerot and Kano, 1985; Kano and Kato, 1987). To date, there has been no characterization of the spatial aspects of LTD in the whole animal in relation to the underlying architectures of the two inputs: the transversely oriented parallel fibers and the parasagittally oriented climbing fibers. The properties of parallel fiber-Purkinje cell LTD predict that the depression will be spatially specific, occurring at the intersection of the evoked parallel fiber and climbing fiber responses (Marr, 1969; Albus, 1971). Electrophysiological recordings in decerebrate animals have been used to test this hypothesis (Ekerot and Kano, 1985; Kano and Kato, 1988) but have limitations in pinpointing the interaction and non-interaction sites and in mapping the spatial properties of the LTD.

Received Sept. 13, 2002; revised Dec. 11, 2002; accepted Dec. 13, 2002.

This work was supported by National Institutes of Health Grant P01-NS 31318 and National Science Foundation Grant DGE 9870633. We thank Yanhua Pan for animal preparation, Michael McPhee for graphics, and Barbara Swanson for preparation of this manuscript.

Correspondence should be addressed to Dr. Timothy J. Ebner, Department of Neuroscience, University of Minnesota, 6-145 Jackson Hall, 321 Church Street S.E., Minneapolis, MN 55455. E-mail: ebner001@umn.edu.

Copyright $\odot 2003$ Society for Neuroscience $\quad 0270-6474 / 03 / 231859-08 \$ 15.00 / 0$
The properties of parallel fiber-Purkinje cell LTD and its cellular and molecular mechanisms have been elucidated in vitro and involves a signaling cascade of activation of group 1 metabotropic glutamate receptors $\left(\mathrm{mGluR}_{1}\right)$ (Aiba et al., 1994; Conquet et al., 1994; Hartell, 1994; Ichise et al., 2000) and protein kinase C (PKC) (Crepel and Krupa, 1988; Linden and Connor, 1991). Nitric oxide-cGMP-protein kinase G cascade is required for LTD induction (Shibuki and Okada, 1991) and is downstream of mGluR activation (Lev-Ram et al., 1997). These signaling cascades result in clathrin-mediated internalization of postsynaptic AMPA receptors (Wang and Linden, 2000). However, the signaling requirements of parallel fiber-Purkinje cell LTD have not been examined in the whole animal.

Recent advances in optical imaging in the cerebellar cortex in vivo using the $\mathrm{pH}$-sensitive dye neutral red allow the visualization of the spatial patterns of activation evoked by stimulating parallel fibers or climbing fibers (Chen et al., 1996, 1998). Stimulation of the former results in a transverse beam of activity parallel to the long axis of the folium, and stimulation of the latter results in parasagittal bands of activity. This optical imaging methodology is based on the highly coupled relationship between neuronal activity and pH change (Roos and Boron, 1981; Chesler, 1990), monitoring primarily intracellular $\mathrm{pH}$ shifts. Neutral red optical imaging yields large, stable optical signals with excellent spatial resolution (Chen et al., 1998), properties needed to monitor gradations in responses over time as well as spatial patterns of activation. Using neutral red imaging in the anesthetized mouse, this study examined the optical correlate of parallel fiber-Purkinje cell LTD, its spatial specificity, and its signaling requirements. 
Parts of this work have been published previously in abstract form (Gao et al., 2001).

\section{Materials and Methods}

Animal preparation. All animal experimentation was approved by the Institutional Animal Care and Use Committee of the University of Minnesota and conducted in conformity with the National Institutes of Health Guide for the Care and Use of Laboratory Animals. Experimental details on the animal preparation and optical imaging techniques have been provided in previous publications (Chen et al., 1998; Hanson et al., 2000) and therefore are only briefly described here. Adult FVB mice (The Jackson Laboratory, Bar Harbor, ME), 3-10 months of age and of either sex, were anesthetized by $1.0 \mathrm{ml} / \mathrm{kg}$ intramuscular injection of a ketamine $(60 \mathrm{mg} / \mathrm{ml})$ and xylazine $(3 \mathrm{mg} / \mathrm{ml})$ mixture. Animals were mechanically ventilated and paralyzed with an intramuscular injection of $0.05 \mathrm{ml}$ of gallamine triethiodide $(20 \mathrm{mg} / \mathrm{ml})$. The animal was placed in a stereotaxic frame, and body temperature was feedback regulated through a rectal temperature probe connected to a heating pad. The electrocardiogram was monitored to assess the depth of anesthesia, allowing anesthetic to be supplemented as needed. After the craniotomy and creation of a watertight chamber around the exposed cerebellar cortex that included crus I and II, the chamber was filled with a Ringer's solution that was gassed with $95 \% \mathrm{O}_{2}$ and $5 \% \mathrm{CO}_{2}$ and contained the $\mathrm{GABA}_{\mathrm{A}}$ receptor blocker bicuculline [0.1 mM; (-)-bicuculline methiodide, $1(S), 9(R)]$ and the $\mathrm{GABA}_{\mathrm{B}}$ receptor blocker hydroxysaclofen $[0.25 \mathrm{~mm}$; $( \pm)-3-$ amino-2-(4-chlorophenyl)-2-hydroxy-propylsulfonic acid]. Initial and supplemental intraperitoneal injections of a $0.2 \mathrm{ml}$ solution of neutral red (35 mM; 3-amino- $m$-dimethylamino-2-methylphenazine hydrochloride) were used to stain the brain. In five mice, MCPG [1 mM; $(R S)$ $\alpha$-methyl-4-carboxyphenylglycine] was added to the Ringer's solution in addition to bicuculline and hydroxysaclofen. All drugs were obtained from Sigma (St. Louis, MO).

Two strains of transgenic mice ages 3-10 months were also used: (1) the homozygous mGluR $_{4}$ knock-out mouse (stock Gprcld ${ }^{\mathrm{tm} 1 \mathrm{Hpn}}$; The Jackson Laboratory) and (2) the L7-PKCI mouse (FVB/N background) that selectively expresses a PKC pseudosubstrate inhibitor in cerebellar Purkinje cells (De Zeeuw et al., 1998).

Electrical stimulation and electrophysiological monitoring techniques. Parallel fiber stimulation (100 $\mu$ sec pulses at $100-200 \mu \mathrm{A}, 10 \mathrm{~Hz}$ for 10 $\mathrm{sec}$ ) was delivered by a tungsten microelectrode (1-3 $\mathrm{M} \Omega$ ) placed just below the cerebellar surface. Inferior olivary stimulation (100 $\mu$ sec pulses at $200-300 \mu \mathrm{A}, 10 \mathrm{~Hz}$ for $10 \mathrm{sec}$ ) was delivered through a second tungsten microelectrode inserted through the dorsal foramen magnum, targeting the contralateral inferior olivary nucleus. The conjunctive stimulation protocol consisted of combined parallel fiber and inferior olive stimulation at $4 \mathrm{~Hz}$ for $10 \mathrm{~min}$ with the parallel fiber stimulation delayed $20 \mathrm{msec}$ (Ekerot and Kano, 1989).

Extracellular recordings of the evoked field potentials were obtained from the molecular layer with glass microelectrodes $(2 \mathrm{M} \mathrm{NaCl}, 2-5 \mathrm{M} \Omega$ ) using conventional electrophysiological techniques (Hanson et al., 2000) during a $16 \mathrm{sec}$ train stimulation $(1 \mathrm{~Hz})$. The $\mathrm{N}_{2}$ component normalized to the $\mathrm{N}_{1}$ wave was used as a measure of the postsynaptic response. The optical imaging allowed the placement of the recording electrode either at the intersection of the parallel fiber stimulation-evoked beam and climbing fiber band or off the intersection but on the beam.

At the end of the experiment, a constant DC current $(200 \mu \mathrm{A}$ for $1 \mathrm{sec}$ for two times) was delivered through the inferior olive stimulating electrode tip to generate a lesion. The animals were then perfused with $4 \%$ paraformaldehyde through the aorta, and the brains were coronally sectioned to determine the exact electrode placement. The data from a mouse were included only if the histology demonstrated that the stimulating electrode was located in the inferior olive.

Optical imaging. Images of the cerebellar surface were acquired by fixing the stereotaxic frame to an $x-y$ stage mounted on a modified Nikon (Tokyo, Japan) epifluorescence microscope with a Quantix 57 cooled charge coupled device camera (Roper Scientific, Tucson, AZ) with 12 bit digitization. The images were binned $2 \times 2$ with a final resolution of $265 \times 256$ pixels $(\sim 10 \times 10 \mu \mathrm{m}$ each pixel $)$. Light from a $150 \mathrm{~W}$ mercury-xenon lamp (Hamamatsu, Shizouka, Japan) powered by an Opti
Quip (Highland Mills, NY) power supply (model 1600) was filtered through a bandpass excitation filter $(546 \pm 5 \mathrm{~nm})$, and the emitted light from the preparation was filtered through a $\geq 590 \mathrm{~nm}$ long-pass filter. A typical acquisition protocol included a series of 20 control frames, followed by series of 150 (single site stimulation) or 400 (concurrent stimulation) experimental frames with $400 \mathrm{msec}$ exposure. Both the parallel fiber and inferior olivary stimulation were initiated at the start of acquisition of the experimental frames.

Data analysis. For display and analysis of the optical signal along the beam, a normalized intensity profile centered on the band evoked by inferior olive stimulation was used. As shown in the insets of Fig. $1 \mathrm{~A}$, a region of interest of 60 pixel $(600 \mu \mathrm{m})$ long and 5 pixels wide $(50 \mu \mathrm{m})$ (shown in red) was positioned on the optical beam and centered on the band evoked by inferior olive stimulation under the guidance of the images generated by subtracting a control frame from the experimental frames. The fluorescence intensity of each pixel was expressed as a function of the background fluorescence, $F_{B}$, that is, $\Delta F / F=\left(F_{E}-F_{B}\right) / F_{B}$. The average of 19 control frames was used as the background fluorescence $\left(F_{B}\right)$, and the average of 19 frames centered on the peak of the optical response was used as the experimental fluorescence $\left(F_{E}\right)$. The five pixels along the width of the region of interest were averaged to generate an intensity profile that was then smoothed using a five-point moving average. Each intensity profile was normalized to its maximum to permit averaging across animals. The resultant averaged intensity profiles of different stimulation conditions and time intervals were used to show the spatial and temporal changes evoked by conjunctive stimulation (Fig. $1 \mathrm{~B}$ ).

The optical response at the interaction region (the intersection of an optical beam and band evoked by conjunctive stimulation) was quantified based on the 10 pixels around the center of the $600 \mu \mathrm{m}$ intensity profile. The $\Delta F / F$ values of these pixels were averaged to provide a measure of the amplitude of optical response in the interaction region. Similarly, the optical response at the "non-interaction region" (regions neighboring the interaction region on the optical beam activated only by surface stimulation) was quantified using the five pixels at each end (10 total) because these regions always fell outside the band-beam interaction region. The $\Delta F / F$ values from the non-interaction regions were also averaged together. These $\Delta F / F$ values for the interaction and noninteraction regions were normalized to baseline control to allow for comparison across groups (Fig. 1C) and plotted as mean \pm SD. ANOVA using a randomized complete block design followed by Duncan's post hoc testing was used to establish the significance of any changes in the amplitude of the optical response before and after the conjunctive stimulation. In the statistics reported, $n$ is the number of animals and equal to the number of interaction sites unless otherwise noted.

To provide a visualization of the location, intensity, and dimensions of the evoked optical beams and bands, a pseudocolored activation map was generated using a program written in Matlab (MathWorks, Natick, MA) (Fig. $1 A$ ). The $\Delta F / F$ of each pixel was normalized to the maximum intensity in that image, and then the normalized $\Delta F / F$ values for each pixel above a threshold were pseudocolored in index true color. The maximal normalized $\Delta F / F$ was set to the greatest red color, and the threshold was set at $50 \%$ of maximum for green for images generated by surface stimulation and inferior olive stimulation. Because the optical responses to inferior olive stimulation generated during the conjunctive stimulation protocol were of lower intensity as a result of the lower frequency stimulation $(4 \mathrm{~Hz})$, the threshold was set to $25 \%$ of maximum. The thresholded, pseudocolored pixels were superimposed on an image of the background fluorescence.

\section{Results}

Activation of the parallel fibers and their postsynaptic targets with a surface electrode evoked an optical response consisting of a narrow, transverse beam (Fig. $1 A, P F$ ), whereas stimulation of the contralateral inferior olive evoked parasagittal bands $(I O)$. In the rodent, $\sim 85 \%$ of the optical beam is attributable to postsynaptic activation, and an even greater percentage of the climbing fiber evoked response is postsynaptic (Chen et al., 1996; Dunbar, 2002). Conjunctive stimulation of the parallel fibers and inferior 

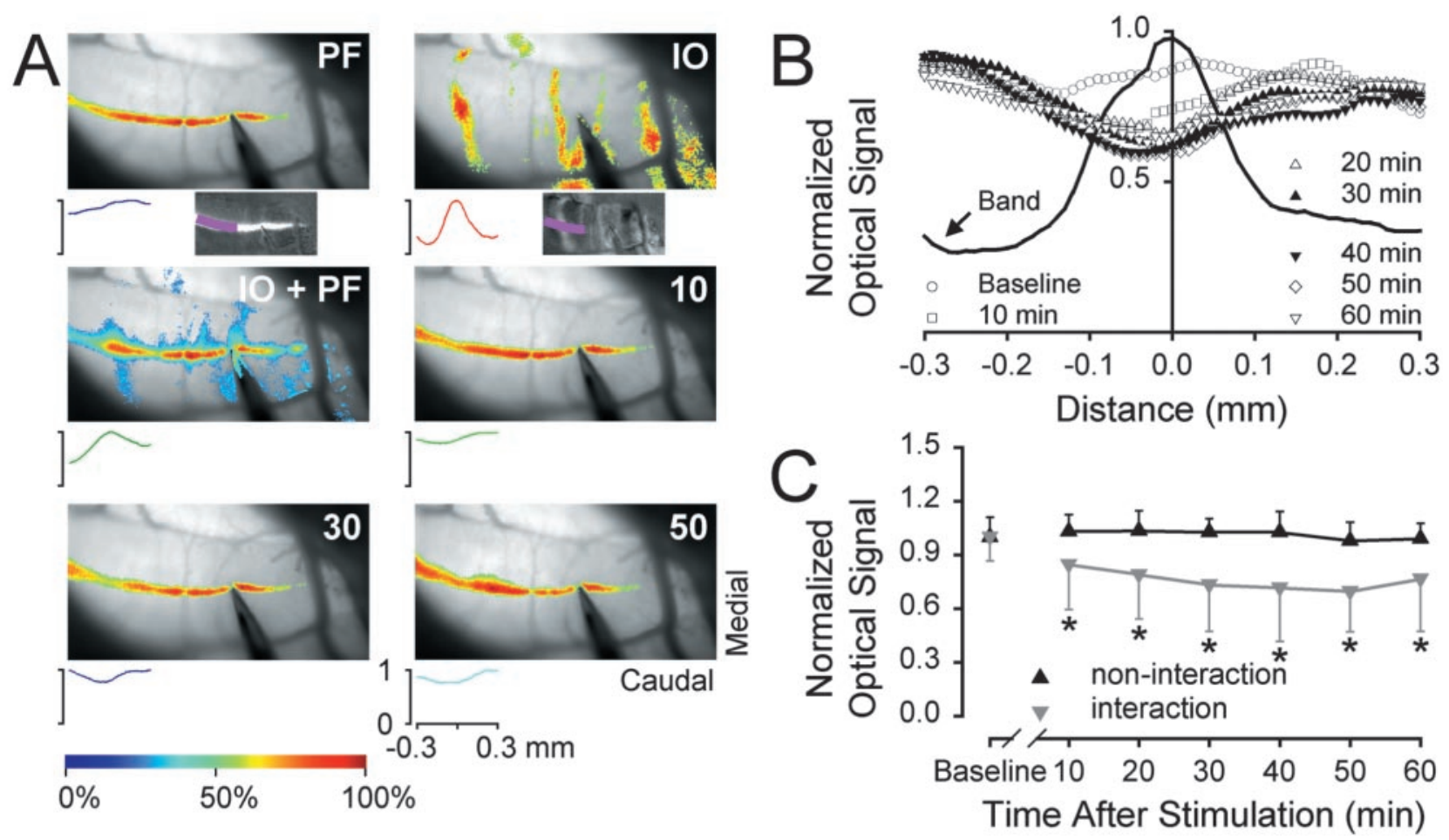

Figure 1. Induction of long-term depression of the optical response to surface stimulation in normal mice. $A$, Pseudocolored optical response in crus Il evoked by baseline surface stimulation (PF), contralateral inferior olive stimulation at $10 \mathrm{~Hz}(10)$, conjunctive stimulation at $4 \mathrm{~Hz}(10+P F)$, and surface stimulation at 10, 30, and 50 min after conjunctive stimulation (10, 30, 50). The pseudocolor scale bar is shown at the bottom left. Below each image is the normalized optical intensity profile of the $0.6 \mathrm{~mm}$ region centered on the site of interaction. To the right of this intensity profile for the $P F$ and 10 images this $0.6 \mathrm{~mm}$ region of the beam is shown superimposed on a subtracted image. Note that the optical response at the site of the strongest beam and band interaction was diminished at 10,30, and $50 \mathrm{~min}$ after conjunctive stimulation. $B$, Average intensity profiles along the beam for $n=11$ animals at different times relative to the conjunctive stimulation. The intensity profiles were averaged after being centered on the band evoked by inferior olive stimulation. After conjunctive stimulation, the optical signal in the interaction region was reduced throughout the $60 \mathrm{~min}$ observation period, with the maximal decrease occurring at the peak of the inferior olive-evoked band. C, Time course of the averaged, normalized optical signal (mean \pm SD) in the non-interaction and interaction regions from these 11 animals. ${ }^{*} p<0.05$ compared with the baseline (Duncan's test, post hoc).

olive using an LTD protocol resulted in a transverse beam with intersecting parasagittal bands $(I O+P F)$. It should be noted that the conjunctive stimulation paradigm $(I O+P F)$ used $4 \mathrm{~Hz}$ stimulation, whereas the images of parallel fiber alone $(P F)$ and contralateral inferior olive $(I O)$ alone were the result of $10 \mathrm{~Hz}$ stimulation. As shown previously, the parasagittal bands are frequency dependent (Hanson et al., 2000); therefore, the evoked parasagittal bands would not be expected to be necessarily identical under these two conditions (see Fig. 3). Subsequent monitoring of the response to parallel fiber stimulation at $10 \mathrm{~min}$ intervals revealed a decrease in the optical beam confined to the site of intersection of the beam and band. The average intensity profiles along the beam demonstrate not only a long-term decrease in the amplitude of the optical response after conjunctive stimulation but also the spatial selectivity relative to the band (Fig. 1B). The location of the maximal depression corresponded to the location of the peak response to inferior olive stimulation along the optical beam. For a group of normal FVB mice $(n=$ 11 ), the decrease in the optical response at the interaction region attributable to conjunctive stimulation was statistically significant (ANOVA; $p<0.001$ ) (Fig. $1 C$ ), which was evident at $10 \mathrm{~min}$ $(15.4 \pm 25.3 \%$ of baseline; mean $\pm S D)$, peaked at $50 \mathrm{~min}$ (30.4 \pm $22.7 \%$ ) after the termination of conjunctive stimulation, and persisted for the duration of observation period (up to $100 \mathrm{~min}$ in two animals). In contrast, the optical response in neighboring non-interaction regions did not significantly differ from preconjunctive stimulation levels (ANOVA; $p>0.05$ ) (Fig. 1C).

Extracellular field potential recordings from the molecular layer were used to evaluate the contributions of the presynaptic and postsynaptic components to the depression in the optical beam. The optical imaging allowed precise placement of the recording electrode in the interaction or non-interaction regions. The field potential evoked by parallel fiber stimulation consisted of the presynaptic parallel fiber $\mathrm{P}_{1} / \mathrm{N}_{1} / \mathrm{P}_{2}$ volley and the postsynaptic $\mathrm{N}_{2}$ component (Fig. $2 \mathrm{~A}$ ). To account for fluctuations in the field potentials over the long recording period, the postsynaptic $\mathrm{N}_{2}$ component was normalized to the presynaptic $\mathrm{N}_{1}$ component (Ito and Kano, 1982). In the interaction region, the normalized postsynaptic component was significantly decreased at the 30-60 min intervals $(n=5$; ANOVA; $p<0.001)$ (Fig. $2 B)$ with a maximal reduction of $51.0 \pm 45.0 \%$ relative to the preconjunctive baseline at $50 \mathrm{~min}$. In the non-interaction region, the field potential recordings did not change significantly $(n=4$; ANOVA; $p>$ 0.05 ) (Fig. $2 A, B$ ). Furthermore, the presynaptic $\mathrm{N}_{1}$ components did not change significantly relative to the preconjunction baseline levels in either the interaction $(n=5$; ANOVA; $p>0.05)$ or non-interaction $(n=4$; ANOVA; $p>0.05)$ regions. Therefore, the electrophysiological results are in agreement with the optical imaging results, confirming that the depression occurs in the postsynaptic response and is restricted to the interaction site.

Activation of mGluR (Aiba et al., 1994; Conquet et al., 1994; Hartell, 1994) and PKC (Crepel and Krupa, 1988; Linden and Connor, 1991) is an essential requirement for LTD in vitro. To determine whether the long-term decrease of the optical signal in the whole mouse demonstrates a similar dependence, two additional groups were studied. In the first, the $\mathrm{mGluR}_{1}$ antagonist 


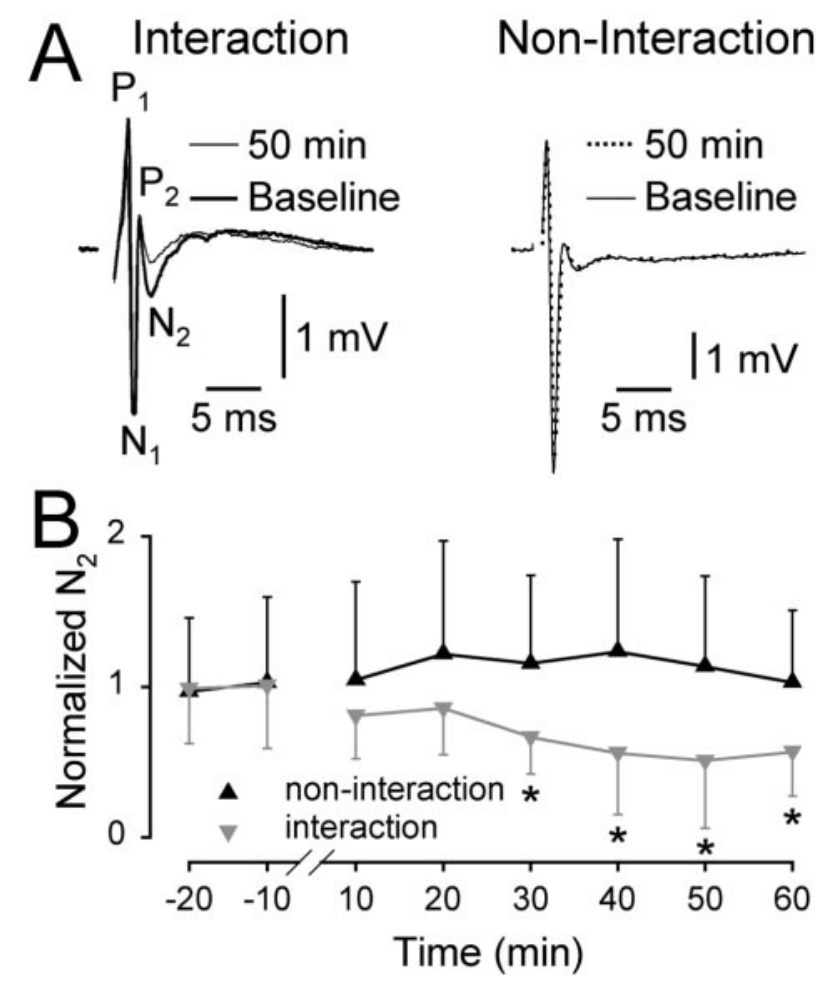

Figure 2. Extracellular field potential recordings in the molecular layer of cerebellar cortex. $A$, Examples of surface-evoked field potentials recorded in the interaction and non-interaction regions before (Baseline) and 50 min after conjunctive stimulation. $B$, Time course of the normalized postsynaptic $\mathrm{N}_{2}$ component in the non-interaction and interaction regions. Data in the interaction region are from five animals and in the non-interaction region from four animals. The postsynaptic component decreased in the interaction region after conjunctive stimulation but did not change in the non-interaction region. ${ }^{*} p<0.05$, indicates a significant change relative to the baseline response (Duncan's test).

MCPG was added to the bath solution. As the example images illustrate (Fig. $3 A$ ), inferior olivary stimulation resulted in several parasagittal bands and one strong interaction site. The optical beam evoked by parallel fiber stimulation was not altered after the conjunctive stimulation. The average intensity profiles of the optical responses along the beam remained relatively uniform (Fig. 3B), and there was no significant change in the optical responses after conjunctive stimulation for either the interaction or non-interaction region $(n=5$ interaction sites in four animals; ANOVA; $p>0.05$ ) (Fig. 3C).

To evaluate the role of $\mathrm{PKC}$, we evaluated transgenic mice (L7-PKCI) that selectively express in cerebellar Purkinje cells a PKC inhibitor that blocks the complete range of PKC isoforms (De Zeeuw et al., 1998; Goossens et al., 2001). The L7-PKCI mice have impaired vestibulo-ocular reflex adaptation in the intact animal and lack LTD in cerebellar slices. Conjunctive stimulation did not result in a significant depression of the optical beam at either interaction or non-interaction regions $(n=5$; ANOVA; $p>0.05$ ) (Fig. 3D-F). Note that, in the L7-PKCI mice, inferior olive stimulation tended to evoke rather wide, diffuse parasagittal bands (Fig. 3D, IO, IO+PF). Therefore, both $\mathrm{mGluR}_{1}$ and PKC are required to generate the long-term decrease in the optical response to surface stimulation in vivo.

Two additional control experiments were undertaken. First, the requirement for conjunctive activation of both climbing fiber and parallel fiber inputs was tested. In this version of the protocol, the contralateral inferior olive was stimulated using the same parameters (4 $\mathrm{Hz}$ for $10 \mathrm{~min}$ ) without parallel fiber stimulation.
For a group of four animals, the intensity profiles along the optical beam remained relatively flat after inferior olive stimulation, and there was no spatially selective depression at the region in which the parasagittal band was evoked (overlapping region) (Fig. 4A). The amplitude of the optical responses at the overlapping and non-overlapping regions did not differ from baseline response before stimulation of the inferior olive $(n=4$; ANOVA; $p>0.05$ ) (Fig. $4 B$ ). Second, to test whether the observed reduction in the optical response is of postsynaptic origin (Ito, 2001), the $\mathrm{mGluR}_{4}$ knock-out mouse was evaluated. It has been shown that $\mathrm{mGluR}_{4}$ are highly expressed in the granule cells of the cerebellum (Tanabe et al., 1993; Kinoshita et al., 1996) and localized presynaptically at the parallel fiber-Purkinje cell synapses (Mateos et al., 1999). In the slice preparation, this knock-out mouse exhibits impaired paired-pulse facilitation and posttetanic potentiation but normal LTD (Pekhletski et al., 1996). Similar to the control mice, the depression in the optical response occurred at the interaction region in this mouse (Fig. $4 C, D$ ). The reduction was significant (ANOVA; $n=4 ; p<0.05$ ), with an average reduction of $15.3 \pm 16.1 \%$ at $10 \mathrm{~min}, 51.3 \pm 29.0 \%$ at 50 $\mathrm{min}$, and $46.1 \pm 10.4 \%$ at $60 \mathrm{~min}$. Conversely, there was no significant change in the optical response in the non-interaction regions (ANOVA; $p>0.05$ ).

\section{Discussion}

The present study provides the first optical imaging of long-term depression of the response to parallel fiber stimulation evoked by conjunctive stimulation of parallel fibers and climbing fibers in vivo. There were several key findings. The depression in the optical beam lasted at least $1 \mathrm{hr}$ and was spatially confined to the site of interaction between the activated parallel fibers and climbing fibers. Field potential recordings confirmed the time course, amplitude, and spatial specificity of the depression. The depression was abolished by the $\mathrm{mGluR}_{1}$ antagonist MCPG and inhibition of Purkinje cell PKC but was normal in the $\mathrm{mGluR}_{4}$ knock-out mouse. This is the first demonstration in vivo that both $\mathrm{mGluR}_{1}$ and PKC activation are required for LTD.

As reviewed recently, there are several types of activitydependent plasticity in the cerebellar cortex (Hansel et al., 2001; Carey and Lisberger, 2002). Therefore, a key question is whether the depression in the optical beam reflects LTD of the parallel fiber-Purkinje cell synapses. Ito (2001) has argued that parallel fiber-Purkinje cell LTD has three key features: a long time course, postsynaptic origin, and input specificity. In addition, as described above, this form of LTD has several essential signaling requirements. The observed depression in the optical signal is completely consistent with these properties and signaling requirements.

Concerning the time course, the depression was detected as early as 10 min after the conjunctive stimulation, reached its peak in $50 \mathrm{~min}$, and lasted more than $1 \mathrm{hr}$, consistent with both in vivo and in vitro findings (Ito and Kano, 1982; Ekerot and Kano, 1985; Karachot et al., 1994). Furthermore, the peak reduction was on the order of $30-50 \%$. The time course and amplitude of the changes in the optical signal were mirrored by the changes in the postsynaptic field potentials. Therefore, the time course and amplitude profile of the depression are consistent with both previous in vivo and in vitro findings.

Several observations demonstrate that the depression is primarily of postsynaptic origin. First, in the mouse, the optical response evoked by cerebellar surface stimulation is $80-85 \%$ postsynaptic (Dunbar, 2002). Therefore, a large component of the depression must be postsynaptic. Second, the field potential 

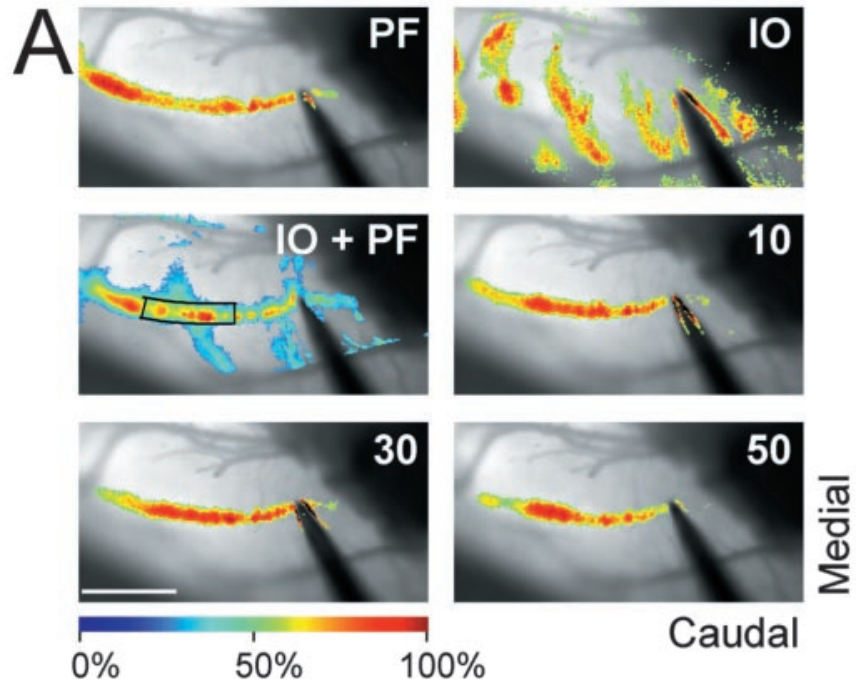

Caudal
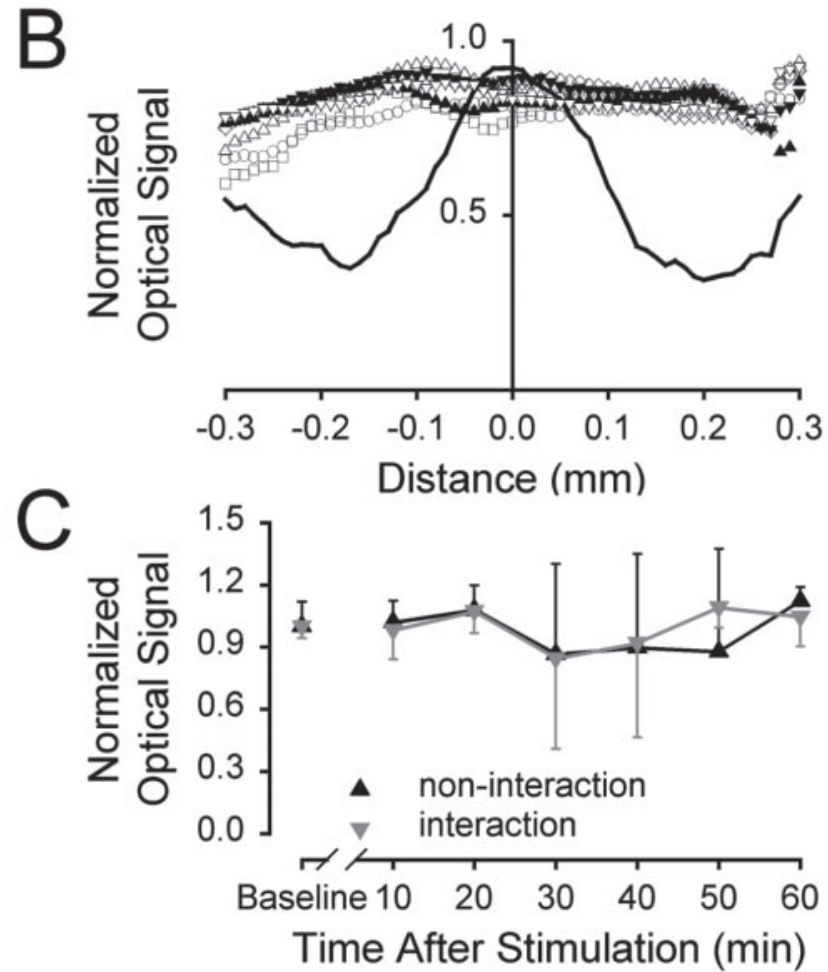
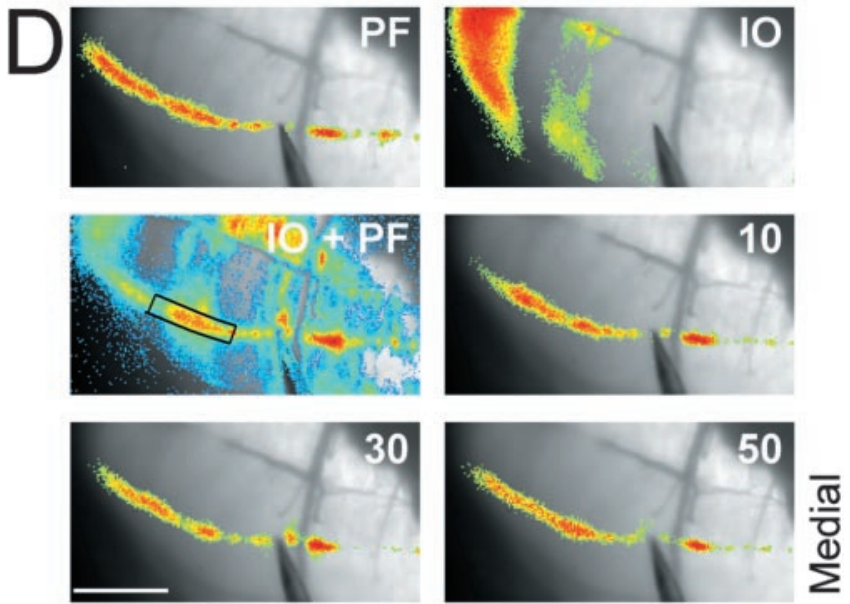

$0 \% \quad 50 \% \quad 100 \%$

Caudal
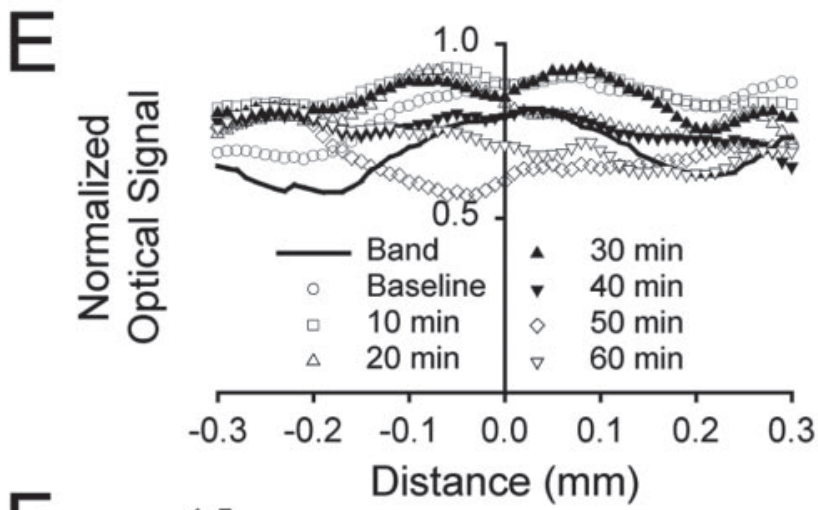

E

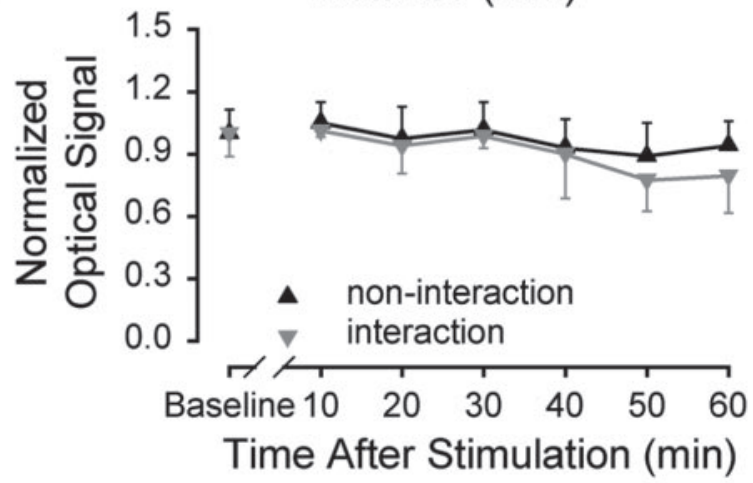

Figure 3. Failure to induce LTD in normal mice with local application of $M C P G(A-C)$ on the cortex and in L7-PKCI mice $(D-F)$. The black outlines in the $/ 0+P F$ images in $A$ and $D$ highlight the site of interaction between the parallel fiber and climbing fiber-evoked response and the $0.6 \mathrm{~mm}$ region of interest analyzed (for details, see Materials and Methods). $A, D, 0$ ptical responses to surface stimulation at various times in relation to conjunctive stimulation and the response to inferior olive stimulation. Conjunctive stimulation failed to result in a long-term change in the optical beam evoked by surface stimulation after blocking mGluR $_{1}(A)$ or with Purkinje cell-specific inhibition of PKC (D). Scale bar, $0.6 \mathrm{~mm}$. $B, E$, Averaged intensity profiles of the optical beam from five animals centered on the inferior olive-evoked band. Across animals, there was no change in the optical response after conjunctive stimulation. $C, F$, Normalized, averaged optical response across the populations did not change in either the interaction or non-interaction regions when compared with baseline.

recordings reveal a decreased postsynaptic $\left(\mathrm{N}_{2}\right)$ component after conjunctive stimulation of similar magnitude and time course without change in the presynaptic parallel fiber component. Furthermore, the depression in the postsynaptic response was localized to the interaction region and was not observed in noninteraction regions. Third, blocking postsynaptic signaling pathways including $\mathrm{mGluR}_{1}$ receptors and PKC in Purkinje cells blocked the long-term depression in the optical response. $\mathrm{mGluR}_{1}$ is localized postsynaptically on Purkinje cell dendrites (Masu et al., 1991) and is not found on parallel fibers (Baude et al., 1993; Lujan et al., 1997). Furthermore, the L7-PKCI mouse expresses the pseudosubstrate inhibitor selectively in Purkinje cells (De Zeeuw et al., 1998). Last, the long-term decrease was present in the mGluR $_{4}$ knock-out mice (Pekhletski et al., 1996). These receptors are found presynaptically at parallel fiber-Purkinje cell synapses (Mateos et al., 1999), and the mGluR mnock- $_{4}$ out mouse has altered presynaptic parallel fiber functioning but normal parallel fiber-Purkinje cell LTD. Together, these observations provide considerable new evidence that the LTD observed in vivo has a postsynaptic origin. 

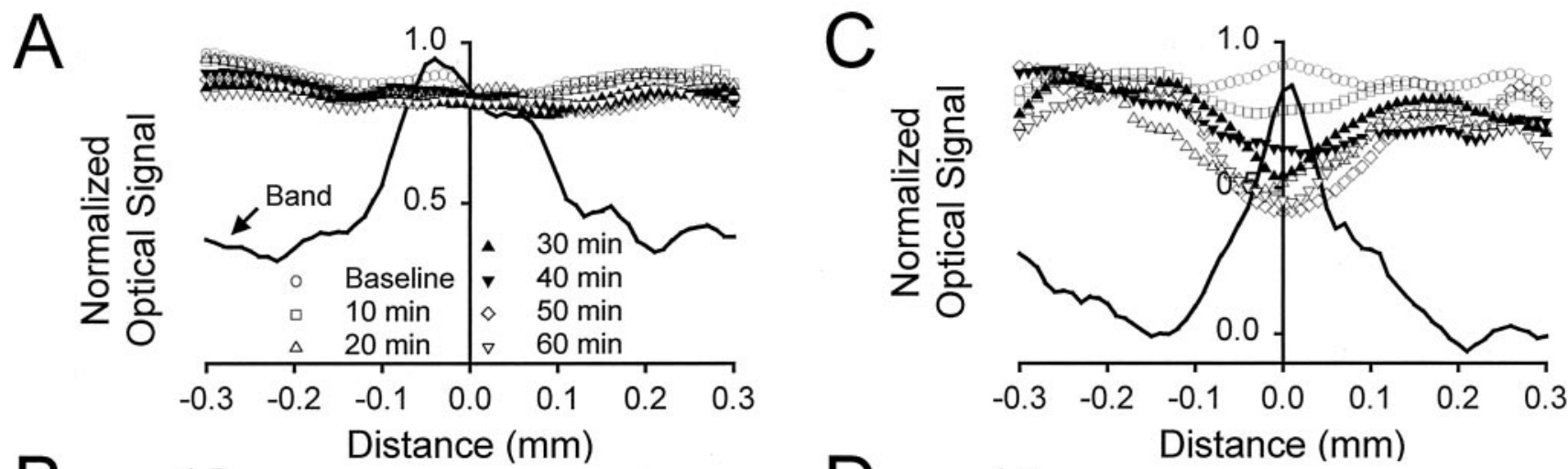

B
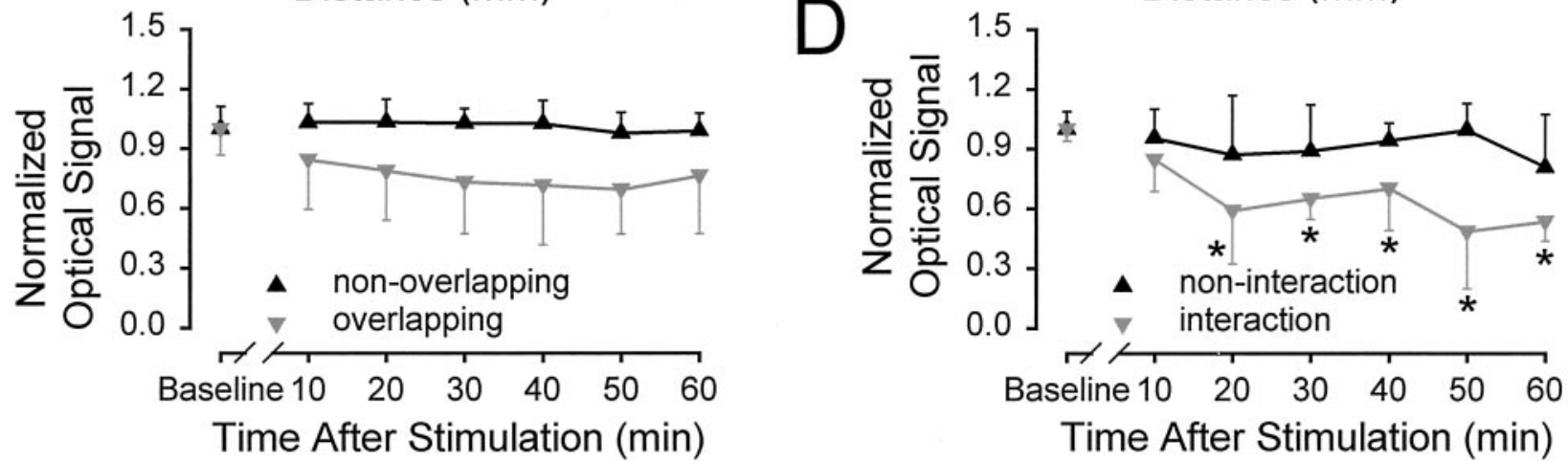

Figure 4. Two additional control experiments. Average, aligned beam intensity profile $(A)$ and time course of the normalized optical signal $(B)$ in normal mice in which only the inferior olive was stimulated instead of the conjunctive stimulation. Data are from four animals. There was no significant change in the beam intensity after conjunctive stimulation either in the region in which parallel fiber beam and climbing fiber band overlap (overlapping) or in the neighboring regions (non-overlapping). C, Average, aligned beam intensity profile in the mGluR $\mathrm{k}_{4}$ knock-out mice and its time course $(D)$. Data are from four animals. After conjunctive stimulation, the normalized optical signal in the interaction region was reduced throughout the 60 min observation period. There was no change in the response in the non-interaction region. ${ }^{*} p<0.05$, indicates a significant change relative to the baseline response (Duncan's test).

Is the depression specific to the parallel fiber-Purkinje cell synapse? Among the known types of synaptic plasticity (Hansel et al., 2001; Carey and Lisberger, 2002) in the cerebellum, the most likely other possibility for the observed depression is rebound potentiation of $\mathrm{GABA}_{\mathrm{A}}$ receptor-mediated interneuron-Purkinje cell synapses (Kano et al., 1992). This possibility needs to be considered because the postsynaptic targets of parallel fibers include not only Purkinje cells but also inhibitory interneurons, which in turn exert a strong inhibition on Purkinje cells and parallel fibers (Eccles et al., 1966; Bisti et al., 1971; Okamoto et al., 1983). This form of long-term potentiation is induced by slow, repetitive activation of climbing fibers (i.e., five pulses at $0.5 \mathrm{~Hz}$ ). Also, the receptive fields of cerebellar interneurons have been shown to increase by pairing peripherally evoked climbing fibers with burst stimulation of parallel fibers (Jorntell and Ekerot, 2002). However, in this study, GABA blockers were used to explicitly exclude any contribution from rebound potentiation of inhibitory interneurons or other forms of plasticity involving inhibitory interneurons. The GABA blockers also facilitate the induction of LTD and expand the effective timing window of conjunctive stimulation (Chen and Thompson, 1995; Bell et al., 1997). Furthermore, the PKC inhibitor mouse results demonstrate that the depression in the optical beam cannot be attributed to other yet to be described forms of LTD, such as LTD of parallel fiber-inhibitory interneuron synapses, because the pseudosubstrate for PKC is selectively expressed in Purkinje cells. Therefore, the long-term decrease in the optical response after conjunctive stimulation is primarily attributable to parallel fiber-Purkinje cell LTD. Again, this level of synaptic specificity for LTD has not been shown previously in vivo.
Another feature of parallel fiber-Purkinje cell LTD is its spatial and input specificity. The parasagittal banding of the climbing fiber afferent projection and the longitudinally organized parallel fibers lead to a specific prediction concerning the spatial properties of LTD: the parallel fiber-Purkinje cell synapses at the intersection of these two systems will be selectively depressed after conjunctive stimulation (Marr, 1969; Albus, 1971). In the present studies, the depression in the optical beam was at the site of interaction of the evoked parallel fiber and climbing fiber responses, with the greatest reduction centered on the evoked climbing fiber band. On average, this interaction region spanned $200 \mu \mathrm{m}$. Field potential recordings on and off the interaction region confirmed the optical imaging results. Furthermore, both parallel fiber and climbing fiber input were required because activation of the climbing fibers without the parallel fibers did not result in a long-term depression in the optical beam. Therefore, the findings complement previous reports that LTD is induced only in a test parallel fiber beam receiving conjunctive climbing fiber activation but not in a control parallel fiber beam separated by $100-300 \mu \mathrm{m}$, demonstrating spatial specificity within a parasagittal band (Ekerot and Kano, 1985; Kano and Kato, 1987; Chen and Thompson, 1995). Compared with previous in vivo studies, the optical imaging approach has several advantages. Optical imaging allows visualization of the long-term depression in the context of the underlying functional architectures: the longitudinally oriented parallel fibers and the parasagittally organized climbing fiber input. Optical imaging also allows visualization of the interaction and the non-interaction regions along the parallel fiber beam and facilitated the accurate placement of the electrode for field potential recordings. Hence, optical imaging provides 
complementary information about the spatial and temporal properties in vivo of LTD.

It has been well established in vitro that $\mathrm{mGluR}_{1}$ and $\mathrm{PKC}$ are essential to the induction of LTD. The present results demonstrate that these factors are also required in the whole animal. The mGluR $_{1}$ antagonist MCPG has been shown to block the glutamate-initiated signal transduction cascade in LTD induction (Eaton et al., 1993) and, in this study, blocked the long-term depression of the optical beam at the interaction region. Similarly, in a transgenic mouse that selectively expresses a PKC inhibitor in Purkinje cells (De Zeeuw et al., 1998), long-term depression of the optical response did not occur after conjunctive stimulation. Because all isoforms of PKC in Purkinje cells are inhibited in L7-PKCI mice, there is no possible compensatory effect from different PKC subspecies as in the PKC $\gamma$ mutant mouse, which has normal parallel fiber-Purkinje cell LTD and eye-blink classical conditioning (Chen et al., 1995). Therefore, not only does the decrease in the optical beam have the three characteristics of parallel fiber-Purkinje cell LTD as defined by Ito (2001), but it is also dependent on two of the critical signaling mechanisms.

One final observation was that the parasagittal bands evoked by inferior olive stimulation appeared wider and more diffuse in the L7-PKCI mice than in the FVB animals (Fig. 3D). This had the effect of reducing the amplitude of the parasagittal band relative to background (Fig. $3 E$ ) and was observed in $\sim 75 \%$ of animals tested. A possible interpretation is the delayed conversion in L7PKI mice from multiple to single climbing fiber innervation of Purkinje cells (De Zeeuw et al., 1998); however, this conversion appears complete at 3 months of age (Goossens et al., 2001). Because the L7-PKI animals studied were 3 months or older, this explanation is unlikely. This observation needs additional study.

A major question is the role of parallel fiber-Purkinje cell LTD in cerebellar function, including the postulated role in motor learning. Cerebellar LTD has been hypothesized to underlie vestibulo-ocular reflex adaptation, eye-blink classical conditioning, and motor skill acquisition (Eccles, 1977; Thach et al., 1992; Lisberger, 1998; Mauk et al., 1998). Needed are studies of how activity-dependent plasticity, such as LTD in the cerebellar cortex, modifies physiological processing and behavior. Optical imaging has the potential to examine the spatial correlates of such changes and to relate LTD to specific behaviors with the development of a chronic optical-behavioral preparation. Analysis of the spatial and temporal properties of LTD during behavioral paradigms may eventually lead to a better understanding of the role of LTD in the cerebellar cortex in general and in the acquisition and retention of motor behaviors in particular.

\section{References}

Aiba A, Kano M, Chen C, Stanton ME, Fox GD, Herrup K, Zwingman TA, Tonegawa S (1994) Deficient cerebellar long-term depression and impaired motor learning in mGluR1 mutant mice. Cell 79:377-388.

Albus JS (1971) A theory of cerebellar function. Math Biosci 10:25-61.

Baude A, Nusser Z, Roberts JD, Mulvihill E, McIlhinney RA, Somogyi P (1993) The metabotropic glutamate receptor (mGluR1 alpha) is concentrated at perisynaptic membrane of neuronal subpopulations as detected by immunogold reaction. Neuron 11:771-787.

Bell CC, Han VZ, Sugawara Y, Grant K (1997) Synaptic plasticity in a cerebellum-like structure depends on temporal order. Nature 387:278-281.

Bisti S, Iosif G, Marchesi GF, Strata P (1971) Pharmacological properties of inhibitions in the cerebellar cortex. Exp Brain Res 14:24-37.

Carey M, Lisberger S (2002) Embarrassed, but not depressed: eye opening lessons for cerebellar learning. Neuron 35:223-226.

Chen C, Thompson RF (1995) Temporal specificity of long-term depres- sion in parallel fiber-Purkinje synapses in rat cerebellar slice. Learn Mem 2:185-198.

Chen C, Kano M, Abeliovich A, Chen L, Bao S, Kim JJ, Hashimoto K, Thompson RF, Tonegawa S (1995) Impaired motor coordination correlates with persistent multiple climbing fiber innervation in $\mathrm{PKC}$ gamma mutant mice. Cell 83:1233-1242.

Chen G, Hanson CL, Ebner TJ (1996) Functional parasagittal compartments in the rat cerebellar cortex: an in vivo optical imaging study using neutral red. J Neurophysiol 76:4169-4174.

Chen G, Hanson CL, Ebner TJ (1998) Optical responses evoked by cerebellar surface stimulation in vivo using neutral red. Neuroscience 84:645-668.

Chesler M (1990) The regulation and modulation of $\mathrm{pH}$ in the nervous system. Prog Neurobiol 34:401-427.

Conquet F, Bashir ZI, Davies CH, Daniel H, Ferraguti F, Bordi F, Franz-Bacon K, Reggiani A, Matarese V, Conde F, Collingridge GL, Crepel F (1994) Motor deficit and impairment of synaptic plasticity in mice lacking mGluR1. Nature 372:237-243.

Crepel F, Krupa M (1988) Activation of protein kinase C induces a longterm depression of glutamate sensitivity of cerebellar Purkinje cells. An in vitro study. Brain Res 458:397-401.

De Zeeuw CI, Hansel C, Bian F, Koekkoek SK, van Alphen AM, Linden DJ, Oberdick J (1998) Expression of a protein kinase C inhibitor in Purkinje cells blocks cerebellar LTD and adaptation of the vestibulo-ocular reflex. Neuron 20:495-508.

Dunbar RL (2002) Imaging two functional architectures and their interaction in the mouse cerebellar cortex in vivo using the $\mathrm{pH}$ sensitive dye neutral red. $\mathrm{PhD}$ thesis, University of Minnesota.

Eaton SA, Jane DE, Jones PL, Porter RH, Pook PC, Sunter DC, Udvarhelyi PM, Roberts PJ, Salt TE, Watkins JC (1993) Competitive antagonism at metabotropic glutamate receptors by $(S)$-4-carboxyphenylglycine and $(R S)$-alpha-methyl-4-carboxyphenylglycine. Eur J Pharmacol 244: 195-197.

Eccles JC (1977) An instruction-selection theory of learning in the cerebellar cortex. Brain Res 127:327-352.

Eccles JC, Llinas R, Sasaki K (1966) Parallel fibre stimulation and the responses induced thereby in the Purkinje cells of the cerebellum. Exp Brain Res 1:17-39.

Ekerot C-F, Kano M (1985) Long-term depression of parallel fibre synapses following stimulation of climbing fibers. Brain Res 342:357-360.

Ekerot C-F, Kano M (1989) Stimulation parameters influencing climbing fibre induced long-term depression of parallel fibre synapses. Neurosci Res 6:264-268.

Gao W, Dunbar RL, Chen G, Finnerty EP, Ebner TJ (2001) Spatial properties of long-term depression in the mouse cerebellar cortex: an in vivo optical imaging study. Soc Neurosci Abstr 27:828.8.

Goossens J, Daniel H, Rancillac A, van der SJ, Oberdick J, Crepel F, De Zeeuw CI, Frens MA (2001) Expression of protein kinase C inhibitor blocks cerebellar long-term depression without affecting Purkinje cell excitability in alert mice. J Neurosci 21:5813-5823.

Hansel C, Linden DJ, D’Angelo E (2001) Beyond parallel fiber LTD: the diversity of synaptic and non-synaptic plasticity in the cerebellum. Nat Neurosci 4:467-475.

Hanson CL, Chen G, Ebner TJ (2000) Role of climbing fibers in determining the spatial patterns of activation in the cerebellar cortex to peripheral stimulation: an optical imaging study. Neuroscience 96:317-331.

Hartell NA (1994) Induction of cerebellar long-term depression requires activation of glutamate metabotropic receptors. NeuroReport 5:913-916.

Ichise T, Kano M, Hashimoto K, Yanagihara D, Nakao K, Shigemoto R, Katsuki M, Aiba A (2000) mGluR1 in cerebellar Purkinje cells essential for long-term depression, synapse elimination, and motor coordination. Science 288:1832-1835.

Ito M (2001) Cerebellar long-term depression: characterization, signal transduction, and functional roles. Physiol Rev 81:1143-1195.

Ito M, Kano M (1982) Long-lasting depression of parallel fiber-Purkinje cell transmission induced by conjunctive stimulation of parallel fibers and climbing fibers in the cerebellar cortex. Neurosci Lett 33:253-258.

Ito M, Sakurai M, Tongroach P (1982) Climbing fibre induced depression of both mossy fibre responsiveness and glutamate sensitivity of cerebellar Purkinje cells. J Physiol (Lond) 324:113-134.

Jorntell H, Ekerot CF (2002) Reciprocal bidirectional plasticity of parallel 
fiber receptive fields in cerebellar Purkinje cells and their afferent interneurons. Neuron 34:797-806.

Kano M, Kato M (1987) Quisqualate receptors are specifically involved in cerebellar synaptic plasticity. Lett Nat 325:276-279.

Kano M, Kato M (1988) Mode of induction of long-term depression at parallel fibre-Purkinje cell synapses in rabbit cerebellar cortex. Neurosci Res 5:544-556.

Kano M, Rexhausen U, Dreessen J, Konnerth A (1992) Synaptic excitation produces a long-lasting rebound potentiation of inhibitory synaptic signals in cerebellar Purkinje cells. Nature 356:601-604.

Karachot L, Kado RT, Ito M (1994) Stimulus parameters for induction of long-term depression in in vitro rat Purkinje cells. Neurosci Res 21:161-168.

Kinoshita A, Ohishi H, Nomura S, Shigemoto R, Nakanishi S, Mizuno N (1996) Presynaptic localization of a metabotropic glutamate receptor, mGluR4a, in the cerebellar cortex: a light and electron microscope study in the rat. Neurosci Lett 207:199-202.

Lev-Ram V, Jiang T, Wood J, Lawrence DS, Tsien RY (1997) Synergies and coincidence requirements between NO, cGMP, and $\mathrm{Ca}^{2+}$ in the induction of cerebellar long-term depression. Neuron 18:1025-1038.

Linden DJ, Connor JA (1991) Participation of postsynaptic PKC in cerebellar long-term depression in culture. Science 254:1656-1659.

Linden DJ, Dickinson MH, Smeyne M, Connor JA (1991) A long-term depression of AMPA currents in cultured cerebellar Purkinje neurons. Neuron 7:81-89.

Lisberger SG (1998) Cerebellar LTD: a molecular mechanism of behavioral learning? Cell 92:701-704.

Lujan R, Roberts JD, Shigemoto R, Ohishi H, Somogyi P (1997) Differential plasma membrane distribution of metabotropic glutamate receptors mGluR1 alpha, mGluR2 and mGluR5, relative to neurotransmitter release sites. J Chem Neuroanat 13:219-241.

Marr D (1969) A theory of cerebellar cortex. J Physiol (Lond) 202:437-470.
Masu M, Tanabe Y, Tsuchida K, Shigemoto R, Nakanishi S (1991) Sequence and expression of a metabotropic glutamate receptor. Nature 349: $760-765$.

Mateos JM, Elezgarai I, Benitez R, Osorio A, Bilbao A, Azkue JJ, Kuhn R, Knopfel T, Grandes P (1999) Clustering of the group III metabotropic glutamate receptor $4 \mathrm{a}$ at parallel fiber synaptic terminals in the rat cerebellar molecular layer. Neurosci Res 35:71-74.

Mauk MD, Garcia KS, Medina JF, Steele PM (1998) Does cerebellar LTD mediate motor learning? Toward a resolution without a smoking gun. Neuron 20:359-362.

Okamoto K, Kimura H, Sakai Y (1983) Effects of taurine and GABA on Ca spikes and $\mathrm{Na}$ spikes in cerebellar purkinje cells in vitro: intrasomatic study. Brain Res 260:249-259.

Pekhletski R, Gerlai R, Overstreet LS, Huang XP, Agopyan N, Slater NT, Abramow-Newerly W, Roder JC, Hampson DR (1996) Impaired cerebellar synaptic plasticity and motor performance in mice lacking the mGluR4 subtype of metabotropic glutamate receptor. J Neurosci 16:6364-6373.

Roos A, Boron WF (1981) Intracellular pH. Physiol Rev 61:296-434.

Sakurai M (1987) Synaptic modification of parallel fibre-Purkinje cell transmission in in vitro guinea-pig cerebellar slices. J Physiol (Lond) 394:463-480

Shibuki K, Okada D (1991) Endogenous nitric oxide release required for long-term synaptic depression in the cerebellum. Nature 349:326-328.

Tanabe Y, Nomura A, Masu M, Shigemoto R, Mizuno N, Nakanishi S (1993) Signal transduction, pharmacological properties, and expression patterns of two rat metabotropic glutamate receptors, mGluR3 and mGluR4. J Neurosci 13:1372-1378.

Thach WT, Goodkin HP, Keating JG (1992) The cerebellum and the adaptive coordination of movement. Annu Rev Neurosci 15:403-442.

Wang YT, Linden DJ (2000) Expression of cerebellar long-term depression requires postsynaptic clathrin-mediated endocytosis. Neuron 25:635-647. 